$A-F$, giving the order $B, F, D, A, C$ for the electrical, and $C, A, B, E, D$ for the optical, method of excitation. Some confusion has, however, arisen, and it may be due to the fact that, when Sponer, Nordheim, Sklar and Teller ${ }^{3}$ suggested their new basis for assignments in the ultra-violet spectra of benzene, they very properly changed Ingold and Wilson's labels. In any event, there appears to be no difference in the order of the intensities, which in both spectra agrees with the Boltzmann factors associated with the progressions.

The other supposed difference relates to the apparently shorter sequences in $160 \mathrm{~cm}^{-1}$ which appear in the electrically excited spectrum. However, the recognition of the nature and classification of the upper electronic state permits an assignment of fluorescence bands which avoids the assumed long sequences in $160 \mathrm{~cm}^{-1}$; and it now appears that with either type of excitation the upper electronic state is able to settle to something like a true Boltzmann distribution with respect to vibration and rotation. These and related matters will be discussed in extenso elsewhere.

Sir William Ramsay and

Ralph Forster Laboratories, University College, London, W.C.1. Sept. 30.

${ }^{1}$ Nature, 156, 368 (1945).

2 Ingold and Wilson, J. Chem. Soc., 941, 955 and 1210 (1936).

J. Chem. Physics, 7, 207 (1939).

\section{Spectra of Diatomic Oxides by the Method of Exploded Wire}

DURING recent years we have developed the method of the exploded wire with the view of its application to the study of molecular spectra, but the circumstances of the German occupation have prevented us from publishing the results. A full account of our investigations by this method (as well as by the method of the aureole of an arc) of $\mathrm{FeO}, \mathrm{NiO}, \mathrm{CoO}$, $\mathrm{CuO}$ and $\mathrm{CaO}$ spectra will be given later in the Bull. Soc. Roy. Sci. Liége.

$\mathrm{FeO}$. We studied the spectrum of $\mathrm{FeO}$ in the yellow during 1940 in collaboration with A. Delsemme, and extended our investigation to the blue and the photographic infra-red during 1942 with L. Malet. Four systems can be represented by :

$$
\begin{aligned}
& v=\left\{\begin{array}{l}
17908 \\
17808
\end{array}\right\}-875 v^{\prime \prime}+5 v^{\prime \prime 2}+\left\{\begin{array}{l}
667 \\
660
\end{array}\right\} v^{\prime} \text { (System A) }
\end{aligned}
$$

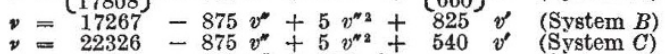

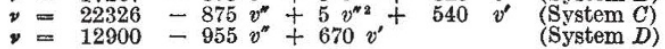

Two short isolated band series ending on the same lower level as the $A, B$ and $C$ bands indicate the existence of $\mathrm{FeO}$ electronic terms at 12,150 and $14,650 \mathrm{~cm}^{-1}$ above this level, which is probably the ground-level of $\mathrm{FeO}$. The classification of the yellow doublets is the same as that proposed by Gaydon and Pearse'.

$\mathrm{NiO}$. We studied the spectra of $\mathrm{NiO}$ and $\mathrm{CoO}$ with L. Malet in 1942. For NiO nearly all the bands observed between 9,070 and 4,145 A. can be fitted into six systems. The constants are given in Table 1.

$\begin{array}{lrc} & & \text { TABLE } 1 . \\ \text { System } & \text { I } & 12655 \\ \text { System } & \text { II } & 13638 \\ \text { System } & \text { III } & 16420 \\ \text { System IV } & 19314 \\ \text { System } & \text { V } & 19602 \\ \text { System } & \text { VI } & 21135\end{array}$

$\begin{array}{lc}\boldsymbol{\omega}^{\boldsymbol{\omega}} & \boldsymbol{\omega}^{\prime} \\ 615 & 475 \\ 590 & 460 \\ 615 & 560 \\ 825 & 590 \\ 820 & 590 \\ 825 & 570\end{array}$

The state with $\omega^{\prime \prime}=615 \mathrm{~cm}^{-1}$ is probably the ground-state of the molecule. The systems II, IV and $\mathrm{V}$ are established with less certainty than the others.

$\mathrm{CoO}$. Bands are observed between 5,000 and $10,000 \mathrm{~A}$. The only characteristic frequeney $\omega^{\prime \prime}=$ $840 \mathrm{~cm} .^{-1}$ can be attributed with great probability to the ground-state of the molecule.

$\mathrm{CuO}$. The spectrum of $\mathrm{CuO}$ was investigated during 1942 in collaboration with J. M. Lejeune. The vibrational analysis of the red $\mathrm{CuO}$ bands showed that they can be represented by:

$$
v=16222-625 v^{\prime \prime}+3 v^{\prime \prime 2}+274 v^{\prime} \text { (System I) }
$$

The green and blue bands observed previously by Hertenstein ${ }^{2}$ can be represented by :

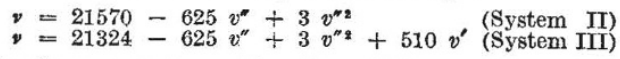

The lower state with $\omega^{\prime \prime}=625 \mathrm{~cm} .^{-1}$ is very probably the ground-state of the molecule.

$\mathrm{CaO}$. This spectrum has been studied during 1942 and 1944 in collaboration with J. M. Lejeune. The main results are summarized in Table 2, which in-

\begin{tabular}{|c|c|c|c|c|c|c|c|}
\hline & $\begin{array}{c}\text { System } \\
a \\
\text { (Meggers } \\
\text { I) }\end{array}$ & $\begin{array}{c}\text { System } \\
\beta \\
\text { (Meggers } \\
\text { II) }\end{array}$ & $\begin{array}{c}\text { TAB } \\
\text { System } \\
\gamma \\
\text { (Orange } \\
\text { bands) }\end{array}$ & $\begin{array}{c}\mathbf{E} 2 . \\
\text { System } \\
8 \\
\text { (Green } \\
\text { bands) }\end{array}$ & $\underset{\varepsilon}{\text { System }}$ & $\begin{array}{c}\text { System } \\
\sigma\end{array}$ & $\begin{array}{c}\text { System } \\
\eta\end{array}$ \\
\hline $\begin{array}{l}v_{0} \\
\omega^{\prime \prime} \\
\omega^{\prime} \\
x^{\prime \prime} \omega^{\prime \prime} \\
x^{\prime} \omega^{\prime}\end{array}$ & $\begin{array}{r}9491 \\
637 \\
674 \\
\sim 7 \\
\sim 5\end{array}$ & $\begin{array}{c}13679 \\
711 \\
694 \\
\sim 3 \cdot 5 \\
\sim 5\end{array}$ & $\begin{array}{r}15947 \\
640 \\
711 \\
\sim 5 \\
\sim 5\end{array}$ & $\begin{array}{r}18260 \\
780 \\
670\end{array}$ & $\begin{array}{r}25191 \\
711 \\
575 \\
\sim 4\end{array}$ & $\begin{array}{r}28054 \\
711 \\
550 \\
\sim 4\end{array}$ & $\begin{array}{r}29330 \\
825\end{array}$ \\
\hline
\end{tabular}
cludes also the revised results of previous investigations on this spectrum.

The state with $\omega^{\prime \prime}=640 \mathrm{~cm}^{-1}$ is probably the ground-state of the $\mathrm{CaO}$ molecule.

All the proposed $\omega$ "-values for the ground-states of the molecules studied are in accordance with the empirical laws governing the $\omega^{\prime \prime}$-values of diatomic oxides.

The results of our investigation on the AlO spectrum by the method of exploded wires, which enabled us to establish several new systems of AlO and to study in some detail the predissociation phenomenon in emission spectra, have already been published ${ }^{3,4}$.

Institut d'Astrophysique,
Université de Liége.

B. ROsEn. July 30.

1 Gaydon, A., G., and Pearse, R. W. B., "Identiflcation of Molecular Spectra".

"Hertenstein, H., Z. wiss. Phot., 11, 69, 119 (1912).

"Coheur, F., and Rosen, B., Bull. Soc. Roy. Sci. Liége, 405 (1941).

- Rosen, B., Bull. Soc. Roy. Sci. Lidge, 176 (1944).

\section{Chromatography of Two Solutes}

WE regret that we cannot agree with the conclusions arrived at by Dr. Glückauf ${ }^{1}$ and that even in the case of the Langmuir isotherm they seem scarcely plausible in the general case.

Our equations can be applied to any suitable adsorption isotherm. In the case of a single solute, the concentration in the developed band is given by our equation:

$$
f^{\prime}(c)=\frac{v}{x}
$$

The corresponding equation for two solutes is :

$$
\left|\begin{array}{cc}
f_{c_{1}}^{\prime}-\frac{v}{x} & f_{c_{2}}^{\prime} \\
g_{c_{1}}^{\prime} & g_{c_{2}}^{\prime}-\frac{v}{x}
\end{array}\right|=0 .
$$

